\title{
Analysis of the robustness of an optimisation model considering uncertainties in water quality parameters.
}

Sayani Dey ( $\square$ sayanidey@students.federation.edu.au )

Federation University Australia - Mount Helen Campus Ballarat

Andrew Barton

Federation University Australia - Mount Helen Campus Ballarat

Adil Bagirov

Federation University Australia - Mount Helen Campus Ballarat

Harpreet Kandra

Federation University Australia - Mount Helen Campus Ballarat

Kym Wilson

Grampians Wimmera Mallee Water Corporation (GWMWater),Horsham

\section{Research Article}

Keywords: Uncertainty analysis, Water quality, Multi-objective optimisation, Trade-offs

Posted Date: January 28th, 2022

DOI: https://doi.org/10.21203/rs.3.rs-1193853/v1

License: (9) This work is licensed under a Creative Commons Attribution 4.0 International License. Read Full License 


\section{Abstract}

The competing nature of water quality and quantity in a complex water resource system makes water management challenging. The difficulty is exacerbated by the uncertainties inherent with the available data. This study performs analysis of uncertainties in water quality data to identify relative changes in stored water volume. The uncertainty analyses are also aimed to assess impact of climate change on water quality. This work uses multi-objective optimisation approach to achieve optimised storage water volume and water quality in a reservoir. The research outcomes indicate that there are trade-offs associated while optimising water quality and quantity levels. It is found that the trade-off curve is insensitive to water quality changes thereby confirming that the model is resilient to water quality uncertainties, particular to this case study area. Therefore, the decision makers can safely rely on these trade-off curves to make decisions on selective harvesting of water. Through this analysis, robustness of the optimisation model is also confirmed and can be applied to future studies to find optimal values of water quantity and quality parameters.

\section{Introduction}

Safe, reliable, and cost-effective water is vital for our health, wellbeing, community social fabric, liveability of our cities and towns, environment, and economy (UN, 2019). However, freshwater is a scarce resource globally (WWAP, 2014). Scarcity of good quality water is a serious problem faced by many regions in the world and more pronounced in a driest continent like Australia (McMahon et al., 1992). Meeting ever increasing water demands is not the only problem, ensuring reliable access to appropriate water quality, for each user, is of equal concern. Therefore, management of water quality and quantity in a complex water resource becomes very crucial.

In water resource management, one of the priority areas is water security (Dickson et al., 2016). Water security is defined as an adequate supply of clean freshwater to always support humans and ecosystems. Water security encompasses both water quantity and quality (Dickson et al., 2016; National Research Council (U.S.), 2001; Norman et al., 2013). However, there is a tendency to focus just on water quantity and not water quality (Gunda et al., 2019; Taylor, 2019). This is because water quality monitoring is a complex process (Behmel et al., 2016). Water quality data is hard to collect, and requires highly specialised, systematic collection and analysis of samples, and is expensive too (Bartley et al., 2012; Behmel et al., 2016).

Monitoring of water quality (both surface and sub-surface) is undertaken for a range of reasons including protecting public health and aquatic ecosystems, environmental reporting, licence compliance and research. Monitoring of water quality is usually a long-term process and needs to be precise and reliable. Due to it being a resource-intensive process, water quality is often not monitored accurately leading to missing and unreliable data. Without accurate, intensive, and long-term data acquisition, the world's water resources cannot be adequately assessed, for effective preservation and remediation programs (Behmel et al., 2016; Kirschke et al., 2020). In Australia, water quality monitoring is carried out by a wide range of 
organisations from local, state, and federal government private sector and community groups (Bartley et al., 2012). But publicly available water quality data could often be discontinuous and scarce.

Salinity and turbidity are two water quality parameters considered in this study. Salinity and turbidity are considered to have significant impact on water quality in a reservoir operating system and vital to be studied (Wurbs, 1996). Knowing the potential impacts of salinity and turbidity, regular monitoring of these two water quality parameters is essential. However available water quality data used in this work is inadequate and discontinuous. Therefore, performing uncertainty analysis of water quality data becomes pertinent in this context.

Uncertainty analyses determine the accuracy of the model outcome. It aims to evaluate the changes in output results due to variability in the input data (Radwan et al., 2004; Refsgaard et al., 2007). In this study uncertainty analysis is performed to quantify the reliability of the parameter inputs (water quality data) in the model. Through this analysis the reliability of the model is also determined.

Multi-objective optimisation modelling approach has been applied in this study as it is an appropriate way to understand the nature of trade-offs between the water quality and quantity in a reservoir system. The trade-off analysis aims to improve reservoir operational decision making and manage water resource system.

The broader research objective of this study is to understand the water quality and quantity interactions for the purpose of operational planning for optimal management of complex water resource system. In order to achieve the research objective, first part of the research study identified and analysed water quantity and quality trade-offs in a water resource system (Dey et al., 2021a). Authors used simulation approach to analyse water quality and quantity trade-offs. Then different operational scenarios were analysed which included increasingly stringent water quality criteria before the water was harvested or by-passed. The storage volume trends were investigated for different water quality levels. Selective harvesting of water from inflow sources was identified as an option to address water quality issues within a reservoir (Dey et al., 2021a). However, authors concluded that the available salinity and turbidity data (Dey et al., 2021a) were not adequately reliable for the study as it generated poor correlation between water quality parameters and the inflows. Therefore, it was recommended to examine the uncertainties associated with salinity and turbidity data used in the study.

The second part of the research used multi-objective optimisation model to achieve optimised storage volume and water quality in the storage. The study by Dey et al. (2021b) developed multi-objective optimisation algorithm to obtain optimal storage volume and its corresponding optimal salinity and turbidity concentrations. Dey et al. (2021 b) also performed sensitivity analysis of NSGA-II (genetic algorithm used in the study) parameters used. Both studies conducted by Dey et al. (2021a, b) have recommended the need to perform uncertainty analysis of water quality parameters. Therefore, it becomes imperative to undertake uncertainty analysis to identify and quantify uncertainties associated with salinity and turbidity water quality data. 
Uncertainty analyses in this study also aims to identify climate change impacts on water quality and water availability. Through this analysis robustness of the optimisation model can be determined. A case study area is selected to which multi-objective optimisation is applied to achieve optimal water quantity and quality on daily basis over 10 years period.

\section{Methods}

\subsection{Study Area}

The Grampians reservoir system is located in arid and semiarid regions of western Victoria, Australia. The Grampians system covers an area approximately $10 \%$ the size of Victoria therefore, an important catchment to be studied (Dey et al., 2021a; Mala-Jetmarova et al., 2015). Many present-day challenges such as water security, water quality variability is associated with this area and makes it an ideal location to be investigated. The Grampians system is a complex reservoir system as it includes 11 interconnected reservoirs and have many other weirs and regulating structures (see Fig. 1).

Taylors Lake, which is one of the eleven reservoirs of the Grampians system, is considered in this study. The reservoir plays an important role in supplying water for agriculture, domestic consumption, and environmental flows to the Wimmera River.

\subsection{Data sources and inputs}

For this study water quality and quantity data were sourced from the Water Measurement Information System (WMIS), Wimmera Catchment Management Authority (WCMA) and Grampians Wimmera Mallee Water (GWMWater). These agencies have been monitoring water flows and water quality at different location in the Grampians System for a very long period. Publicly available data such as daily streamflow, turbidity and monthly turbidity and electrical conductivity data were directly retrieved from WMIS website (DELWP, 2020). Other turbidity and conductivity data were taken from WCMA website (WCMA, 2020). The remaining data were obtained from GWMWater.

The input dataset consists of hydrological data, reservoir operational data, and meteorological data. Inflow data, turbidity, and conductivity data were used on a daily time step from 2010-2019. Three major inflow sources were determined depending on availability of daily streamflow data, and their corresponding turbidity and electrical conductivity data. In some instances, exact water quality data related to the same location were not available. Therefore, water quality data of a nearby location were used. Some inflow locations did not include the daily data so monthly point data were taken into consideration to find a relation between available water quality and its corresponding stream flow at that time.

\subsection{Methods}

The steps involved to carry out uncertainty analysis is depicted in Fig. 2. Data input, data input scenarios, data conversion, and regression analysis together are represented as data processing. Data processing 
followed by simulation and multi-objective optimisation approach were used to perform uncertainty analysis and are discussed further.

\subsubsection{Data processing}

Initial work analysed water volume changes in the storage with raw water quality data (base result) and this has been described in Dey et al. (2021a). Regression correlation between inflows and salinity, inflows and turbidity were assessed. This then helped to carry out the trade-offs analysis between water quantity and quality and resulted in preliminary outcomes. With increasing water quality restriction, it was observed that there is a decrease in water quantity in the storage. Through scenario analysis, existence of various levels of trade-offs between water availability, salinity and turbidity was established. In the subsequent work by Dey et al. (2021b) multi-objective optimisation was applied to obtain Pareto fronts, which provided optimal storage volume and optimal salinity and turbidity concentrations.

In this work relative changes of water quantity values will be analysed with water quality alterations: the parameter values were perturbed by $\pm 10 \%$ and $\pm 25 \%$. $\pm 10 \%$ and $\pm 25 \%$ uncertainty percentage used, were based on assumption representing extreme uncertainties. Step by step data processing for purpose of performing uncertainty analysis is given below:

- For undertaking the analysis, first the values of parameters: electrical conductivity, and turbidity were perturbed by $+10 \%$ and $+25 \%$ and then by $-10 \%$ and $-25 \%$.

- The modelling tool used in this research (eWater Source ${ }^{\circledR}$ ), could not express salinity and turbidity in micro-Siemens $(\mu \mathrm{S} / \mathrm{cm})$ and nephelometric unit (NTU) respectively. So, it was required to express both water quality parameters in milligram per litre $(\mathrm{mg} / \mathrm{L})$. Salinity and turbidity were therefore expressed as total dissolved solids (TDS) and total suspended solids (TSS) respectively to carry out the study (Dey et al., 2021a).

- The generated set of electrical conductivity $(\mu \mathrm{S} / \mathrm{cm}$ ) data were converted to TDS (mg/L). Commonly used conductivity-TDS unit conversion relationship is TDS $(\mathrm{mg} / \mathrm{L})=$ electrical conductivity $(\mu \mathrm{S} / \mathrm{cm}) \mathrm{X}$ 0.6 (Jeznach et al., 2016).

- Exponential regression curve was applied to establish the relationship between inflow and TDS for three different inflow sites respectively. Using the exponential regression, TDS values from its corresponding inflows were developed (Dey et al., 2021a).

- Next step was to process turbidity and TSS datasets. Linear site-specific relationship was established between turbidity and TSS. Commonly used linear relationship is TSS $(\mathrm{mg} / \mathrm{L})=\mathrm{m}$ turbidity (NTU), where $m$, is the slope (Rügner et al., 2013). Expected $m$ value ranges between 1 to 2.5. Turbidity values were then converted to TSS using the correlation.

- Logarithmic correlation was applied to develop relationship between TSS and inflow for three different inflow sources. Using the logarithmic expression, TSS values from its corresponding inflows were then generated in the model (Dey et al., 2021a). 


\subsubsection{Simulation and optimisation}

A combined simulation and optimisation approach was adopted to carry out the uncertainty analysis. The software eWater Source ${ }^{\circledR}$ (Blackmore et al., 2009) version 4.11 .0 was chosen for this study as it combines a hydrologic simulation engine with inbuilt optimisation tool. The simulation engine was used to execute water balance and mass balance over 10 years period. Insight, which is the inbuilt optimisation engine in Source ${ }^{\circledR}$ carried out the optimisation run with three objective functions, and decision variables. The NSGA-II (Deb et al., 2002) genetic algorithm was used in this study, as it was the default algorithm present in the optimisation tool. The management objective of the study looked at both water quality and quantity. Therefore, two types of objective functions, water quantity (water availability) and water quality (salinity and turbidity) were developed. A detailed study on multi-objective optimisation can be found in Dey et al. (2021b). Fig. 3 below is a flow chart representing how the simulation and the optimisation engine works together in the software.

\subsubsection{Uncertainty analysis}

Multi-objective optimisation was performed using base case scenario as the water quality objective can be achieved by using the same optimisation algorithm for different water quality uncertainty scenarios.

Scenario analysis required manual changing of water quality threshold to see the effect of water quality restriction on stored water volume. But in optimisation specified objective functions (storage water quantity and quality) operates within the set of operating rules (decision variables) and does not require changing the water quality threshold each time. The optimisation algorithm works within the parameter limits (in this case salinity and turbidity thresholds). Hence, with predefined set of optimisation algorithm multi-objective optimisation was performed for raw water quality scenario (base scenario) and for different level of uncertainty scenarios. Following steps were undertaken to perform uncertainty analysis:

- Three objective function algorithms defining water quantity and quality were identified and configured in the model using function editor present in the software (Dey et al., 2021b).

- Population size of 200, generation number of 10 , crossover of 0.95 and mutation of 0.5 were used to configure the model. Where, population size represents set of solutions (decision variables), number of generation determines better quality outcomes (optimal results), crossover and mutation are the process to improve the quality of outcomes. The sensitivity of these NSGA-Il parameter settings was determined in previous study conducted by Dey et al. (2021b).

- Five uncertainty scenarios representing, base (raw water quality), $+10 \%$ (raw water quality data increased by $+10 \%$ ), $-10 \%$ (raw water quality data decreased by $-10 \%$ ), $+25 \%$ (raw water quality data increased by $+25 \%$ ) and $-25 \%$ (raw water quality data decreased by $-25 \%$ ) were identified and set up.

- Five different scenarios were configured with the same optimisation algorithm but with different water quality input dataset. Observations will help to understand how sensitive the result output is with changed water quality input data. Separate optimisation runs were performed for each scenario. 
The working principle of the simulation-optimisation model is shown in Figure 3 and detailed study on optimisation is presented in Dey et al. (2021b).

- Results obtained provided optimised storage water volume and optimised water quality for base scenario and four different uncertainty scenarios.

- The uncertainty scenarios were then compared with the base result to investigate water quantity and quality changes and to determine robustness of the optimisation model.

\section{Results}

This section provides the results obtained from multi-objective optimisation runs of the model. The observed data used, was for 10 years period from 2010-2019. The data sets for base scenario (raw water quality data) and for different scenarios of uncertainty analysis $\pm 10 \%$ and $\pm 25 \%$ are presented in this section.

The results section provides a glimpse of the optimised water quantity and quality outcomes. Optimised storage volume, and its corresponding salinity $(\mathrm{mg} / \mathrm{L})$ and turbidity $(\mathrm{mg} / \mathrm{L})$ concentrations are presented. However, these optimised results are the average values over 10 years. Pareto fronts of the raw data set are compared with Pareto fronts of $\pm 10 \%$ and $\pm 25 \%$ water quality modifications. The purpose of representing optimised outcomes is to understand whether the nature of trade-offs is affected with uncertainties in data. The deviations of the Pareto fronts help the water managers to plan for any future condition changes in the reservoir.

Figure 4 compares the base scenario (raw water quality data input) with $\pm 10 \%$ water quality uncertainty scenarios. Optimised storage volume is plotted against optimised salinity and turbidity concentrations. Average optimised storage volume is around $19,000 \mathrm{ML}$ for base case and for $\pm 10 \%$ uncertainty scenarios. In the base scenario, optimised salinity of the stored water ranges between 30-150 mg/L. Salinity increases to $40-160 \mathrm{mg} / \mathrm{L}$ with $+10 \%$ uncertainty and decreases to $30-130 \mathrm{mg} / \mathrm{L}$ with $-10 \%$ change in uncertainty. Optimal value of the turbidity concentration of storage water ranges between 10$25 \mathrm{mg} / \mathrm{L}$ for the base scenario. With perturbation in uncertainty by $+10 \%$ the turbidity concentration ranges between $12-27 \mathrm{mg} / \mathrm{L}$ and decreases to $7-22 \mathrm{mg} / \mathrm{L}$ with perturbation in uncertainty by $-10 \%$. The graph indicates that trade-offs between water quality and quantity prevails even with modified water quality data inputs.

Base scenario along with uncertainty scenarios of $\pm 25 \%$ is presented in Fig. 5 . Optimised storage volume with optimised salinity and turbidity are plotted. The average storage volume is around 19,000 ML for base and $\pm 25 \%$ uncertainty scenarios. Even though the storage volume remains almost same the optimised salinity and turbidity concentrations varies substantially with changed uncertainty percentage. In the base scenario, optimised salinity of the stored water ranges between 30-150 mg/L and turbidity ranges between $10-25 \mathrm{mg} / \mathrm{L}$. Then with $+25 \%$ water quality data alteration salinity, and turbidity ranges between $50-190 \mathrm{mg} / \mathrm{L}$ and 15-34 $\mathrm{mg} / \mathrm{L}$ respectively. In -25\% uncertainty scenario salinity and turbidity 
ranges between $24-104 \mathrm{mg} / \mathrm{L}$ and $4-15 \mathrm{mg} / \mathrm{L}$ respectively. There is a significant difference between water quality values of the two uncertainty $(+25 \%$ and $-25 \%)$ scenarios when compared to the base scenario.

Figure 6 represents Pareto fronts obtained after multi-objective optimisation. Uncertainty of $\pm 10 \%$ is shown in the figure. Three dimensional representations of three objective functions - storage volume, salinity and turbidity are shown. The competing nature of the objective functions are evident in the figure. With an optimised storage volume of $19,000 \mathrm{ML}$, the salinity seems to increase while turbidity values tend to decrease. Maximum turbidity concentration was around $25 \mathrm{mg} / \mathrm{L}$ and that of salinity was around 125 $\mathrm{mg} / \mathrm{L}$. There is almost no difference between stored water volume with the base water quality conditions and $\pm 10 \%$ water quality changes.

Figure 7 represents Pareto fronts of base results compared with uncertainty scenarios of $\pm 25 \%$. The trade-offs between water quantity and quality were established. Three different competing objective functions (storage volume, salinity, and turbidity) are shown in the figure and presented on each axis. With uncertainty percentage of $25 \%$ there are visible difference in the results. Average optimal value of the storage volume is around $19,000 \mathrm{ML}$ for all the scenarios. But there are changes to optimal salinity and turbidity concentrations with changes in uncertainty percentage. For example, the maximum salinity concentration in the base case was $150 \mathrm{mg} / \mathrm{L}$, which increased to $190 \mathrm{mg} / \mathrm{L}$ with $+25 \%$ change in uncertainty. Similarly, there was an increase in turbidity concentration from $25 \mathrm{mg} / \mathrm{L}$ to $35 \mathrm{mg} / \mathrm{L}$ with $+25 \%$ change in uncertainty .

Unlike $\pm 10 \%$ changes, where difference between stored water volume is negligible, $\pm 25 \%$ changes have visible difference in stored water volume. Optimised salinity and turbidity vary considerably between all the uncertainty scenarios, i.e., $\pm 10 \%$ and $\pm 25 \%$. With increased uncertainty percentage the difference in the storage volume becomes notable. Even though, there is difference between water quality and quantity values with different uncertainty percentage, there is no change in the nature of the trade-off which exists between water quality and quantity.

\section{Discussions}

Auditing water quantity is vital in water resource management, but regular assessment of water quality is equally important to identify the trends to maintain and improve regions water quality. Irregularity in water quality monitoring may affect model outputs and subsequent applications of model. Addressing water quality ambiguities can help to develop effective water quality and quantity models which can be adopted by water managers or system operators to manage reservoir system efficiently and addressing uncertainties will help to determine reliability of the model.

Previous study conducted by Dey et al. (2021b), used simulation and optimisation method to investigate the nature of trade-offs between water availability, salinity, and turbidity. The study aimed to help water managers to make informed operational decisions around selective harvesting of inflows in order to achieve better water quality conditions in the storage. However, the effects of water quality changes on 
the model outcome was unclear. The research work presented in this paper attempted to address uncertainty associated with water quality data in an organised way.

Inadequate and discontinuous water quality data caused poor regression relationship between water quality and the inflow, hence prompted to perform uncertainty analysis of water quality data. The flow data used in this study is also discontinuous but it is not considered for uncertainty analysis as the stakeholders of this study area are more interested in the water quality aspect. Climate change effects related to water quality is the focus of this study and future work will consider the uncertainty related to flow data. Uncertainty tests of water quality data were performed. Simulation and optimisation were performed with $\pm 10 \%$ and $\pm 25 \%$ changes in water quality data. The work attempted to inform the effect of different water quality uncertainty scenarios on the storage volume levels. The observed results suggested that with $\pm 10 \%$ uncertainty the optimised results did not alter much, but when approaching $\pm 25 \%$ deviation, there were changes in the optimised result. The uncertainty analysis performed did not change the nature of trade-off between water quantity and quality. The results indicated that even though there are discontinuities in water quality data, the decision makers can safely rely on the trade-off curve to make decisions on selective harvesting of water, specifically in this case. Thus, this study provides crucial insights to water managers in operational planning related to future condition changes such as climate change.

Research has shown that climate changes observed over recent decades will continue in future and will become more severe (CSIRO, 2020). Hot days will become much hotter, extreme rainfall will intensify causing serious water related complications. With such severe climate change predictions, water managers will find it even more challenging to manage water resources. The specific case study area has already observed such extreme events in past decade, which led to water restrictions and deterioration in water quality (DELWP, 2016). Therefore, this research outcome would inform managers about extreme climate conditions affecting water quality and thereby helping day-to-day planning. The geography of the study site is prone to dry weather which intensifies the salt concentrations in the water leading to high salinity and managers have no other choice, apart from harvesting the poor-quality water to meet demand. With such water quality problems, managers can refer to the results presented in this study to harvest potential quantity of water with optimised water quality levels. This will also assist to foresee the water quality concerns and harvest water depending on the water quality conditions of the inflow sources. However, this study did not analyse several other uncertainties related to inflow data, and spatial variations which need to be investigated.

Additionally, the uncertainty analysis conducted in this study assisted to conclude that multi-objective optimisation algorithm used for this study is efficient. Observations suggested that with changed water quality input dataset the output results remained same. In particular, the nature of trade-offs between water quality and quantity of this location remained same, hence confirming robustness of the optimisation model. Therefore, this approach can be utilised for future studies to conduct water quantity and quality optimisation. 


\section{Conclusions}

The research work in this paper provided an insight into the uncertainties associated with water quality data. Due to the inadequate water quality data, it was imperative to perform water quality uncertainty analysis. The work commenced with stepwise processing of water quality data followed by simulation and multi-objective optimisation. The results indicated the competing nature between water quality and quantity. The trade-off curve was insensitive to water quality changes confirming that the model is resilient to water quality uncertainties particular to this case area. Therefore, decision makers can depend on these trade-off curves to make decisions on selective harvesting of water. Through this analysis robustness of the optimisation model was also confirmed.

There are limitations to this research work. Only water quality uncertainty was considered in this work. But there could be other uncertainties associated with inflow data and spatial variabilities, which can affect the model performance. Therefore, future work needs to investigate flow data, spatial changes affecting the model.

\section{Declarations}

\section{Acknowledgments}

This work is supported by both Australian Research Training Program and Grampians Wimmera Mallee Water (GWMWater).

Funding This work is financially supported by Grampians Wimmera Mallee Water Corporation (GWMWater).

Competing interests The authors declared that they have no competing interest to this work.

Availability of data and materials Department of Environment, Land, Water and Planning (DELWP), Victoria Australia, Grampians Wimmera Mallee Water Corporation, Victoria Australia, Wimmera Catchment Management Authority Victoria Australia.

Code availability Not applicable

Authors' contributions Conceptualization: S. Dey and A. Barton, Method: S. Dey and A. Barton, Data collection and analysis: S. Dey, Writing original draft preparation: S. Dey, Writing- editing and review: A. Barton, H. Kandra, A. Bagirov and K. Wilson.

Ethics approval Not applicable

Consent to participate Not applicable

Consent to publish Not applicable 


\section{References}

1. (CSIRO) Commonwealth Scientific and Industrial Research (2020) $24 / 12 / 2020$ ). Climate change in Australia. The most comprehensive climate projections for Australia. Retrieved from https://www.csiro.au/en/research/environmental-impacts/climate-change/Climate-changeinformation

2. Managing extreme water shortage in Victoria (ISBN 978-1-76047-046-3 (pdf)). Retrieved from (DELWP) Department of Environment Land and Water Planning, Victoria (2016) Australia: https://www.water.vic.gov.au/_data/assets/pdf_file/0017/512720/DELWP-MillenniumDrought-webSB.pdf.pdf

3. (DELWP) Department of Environment Land and Water Planning (2020) Water Measurement Information System. Retrieved March 2020 https://data.water.vic.gov.au/

4. (UN) United Nations (2019) Sustainable Development Goals. Goal 6: Ensure access to water and sanitation for all. Retrieved from https://www.un.org/sustainabledevelopment/water-and-sanitation/

5. WCMA) Wimmera CMA (2020) River flow. Retrieved April 2020 https://wcma.vic.gov.au/rivers-andstreams/river-flows

6. Bartley R, Speirs WJ, Ellis TW, Waters DK (2012) A review of sediment and nutrient concentration data from Australia for use in catchment water quality models. Mar Pollut Bull 65(4):101-116. doi:https://doi.org/10.1016/j.marpolbul.2011.08.009

7. Behmel S, Damour M, Ludwig R, Rodriguez MJ (2016) Water quality monitoring strategies - A review and future perspectives. Sci Total Environ 571:1312-1329.

doi:https://doi.org/10.1016/j.scitotenv.2016.06.235

8. Blackmore J, Dandy G, Kuczera G, Rahman J (2009) Making the most of modelling: A decision framework for the water industry. Paper presented at the Proceedings of the 18th World IMACS/MODSIM Congress, Cairns, Australia

9. Deb K, Pratap A, Agarwal S, Meyarivan T (2002) A fast and elitist multiobjective genetic algorithm: NSGA-II. IEEE Trans Evol Comput 6(2):182-197. doi:doi: 10.1109/4235.996017

10. Dey S, Barton A, Kandra H, Bagirov A, Wilson K (2021a) Analysis of Water Quantity and Quality Trade-Offs to Inform Selective Harvesting of Inflows in Complex Water Resource Systems. Water Resour Manage 1-17. doi:https://doi.org/10.1007/s11269-021-02936-x

11. Dey S, Barton A, Kandra H, Bagirov A, Wilson K (2021b) Multi-objective optimisation to manage tradeoffs in water quality and quantity of complex water resource system. Paper presented at the Hydrology and Water Resources Symposium, Virtual Symposium,conducted by Engineers Australia

12. Dickson SE, Schuster-Wallace CJ, Newton JJ (2016) Water Security Assessment Indicators: The Rural Context. Water Resour Manage 30(5):1567-1604. doi:10.1007/s11269-016-1254-5

13. Gunda T, Hess D, Hornberger GM, Worland S (2019) Water security in practice: The quantity-qualitysociety nexus. Water Security 6:100022. doi:https://doi.org/10.1016/j.wasec.2018.100022 
14. GWMWater (2016) Storage Management Rules for the Wimmera-Mallee System Headworks. Retrieved from http://www.storagemanager.com.au/component/edocman/688-storage-managerrules-for-the-wimmera-mallee-system-headworks-updated-august-2016-pdf/download

15. Jeznach LC, Jones C, Matthews T, Tobiason JE, Ahlfeld DP (2016) A framework for modeling contaminant impacts on reservoir water quality. J Hydrol 537:322-333. doi:https://doi.org/10.1016/j.jhydrol.2016.03.041

16. Kirschke S, Avellán T, Bärlund I, Bogardi JJ, Carvalho L, Chapman D, Warner S (2020) Capacity challenges in water quality monitoring: understanding the role of human development. Environ Monit Assess 192(5):298. doi:10.1007/s10661-020-8224-3

17. Mala-Jetmarova H, Barton A, Bagirov A (2015) Impact of Water-Quality Conditions in Source Reservoirs on the Optimal Operation of a Regional Multiquality Water-Distribution System. J Water Resour Plan Manag 141(10):04015013. doi:doi:10.1061/(ASCE)WR.1943-5452.0000523

18. McMahon, Finlayson B, Haines A, Srikanthan R (1992) Global runoff: continental comparisons of annual flows and peak discharges. Catena Verlag

19. National Research Council (U.S.) (2001) Envisioning the Agenda for Water Resources Research in the Twenty-First Century. National AcademiyPress

20. Norman ES, Dunn G, Bakker K, Allen DM, de Cavalcanti R (2013) Water Security Assessment: Integrating Governance and Freshwater Indicators. Water Resour Manage 27(2):535-551. doi:10.1007/s11269-012-0200-4

21. Radwan M, Willems P, Berlamont J (2004) Sensitivity and uncertainty analysis for river quality modelling. J Hydroinformatics 6(2):83-99. doi:10.2166/hydro.2004.0008

22. Refsgaard JC, van der Sluijs JP, Højberg AL, Vanrolleghem PA (2007) Uncertainty in the environmental modelling process - A framework and guidance. Environ Model Softw 22(11):15431556. doi:https://doi.org/10.1016/j.envsoft.2007.02.004

23. Rügner H, Schwientek M, Beckingham B, Kuch B, Grathwohl P (2013) Turbidity as a proxy for total suspended solids (TSS) and particle facilitated pollutant transport in catchments. Environ Earth Sci 69(2):373-380. doi:https://doi.org/10.1007/s12665-013-2307-1

24. Taylor KS (2019) What does 'water security'mean for Australia? A review of Australian policy. Parliamentary Library's Annual Summer Scholar Program; Parliament of Australia: Canberra, ACT, Australia

25. Wurbs RA (1996) Modeling and analysis of reservoir system operations. Prentice Hall

26. WWAP. The United Nations World Water Development Report 2014: Water and Energy. Paris UNESCO (2014) Retrieved from http://www.unesco.org/new/en/naturalsciences/environment/water/wwap/wwdr/2014-water-and-energy/

\section{Figures}




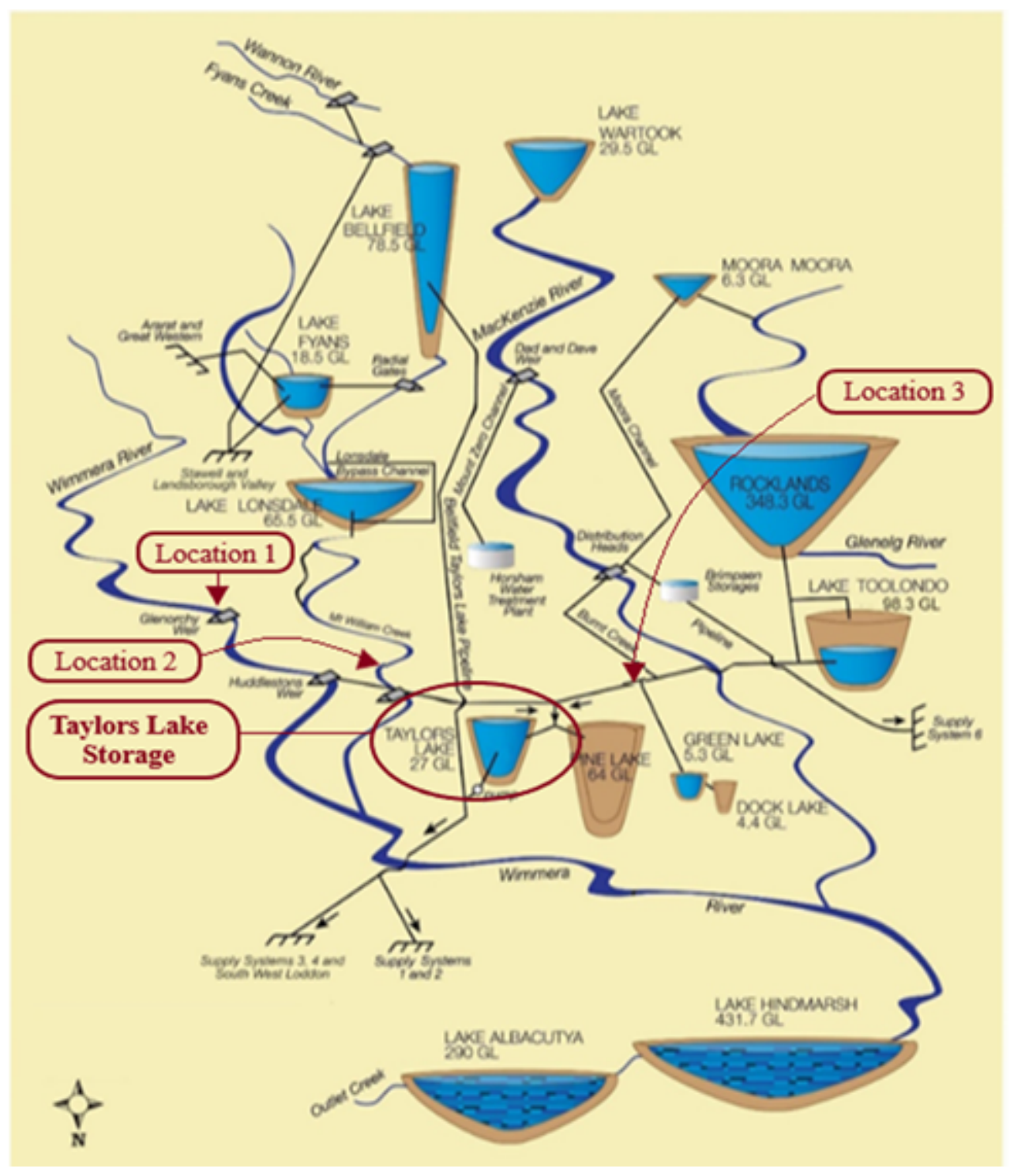

Figure 1

The Grampians Reservoir System (Source: adapted from (GWMWater, 2016)) 


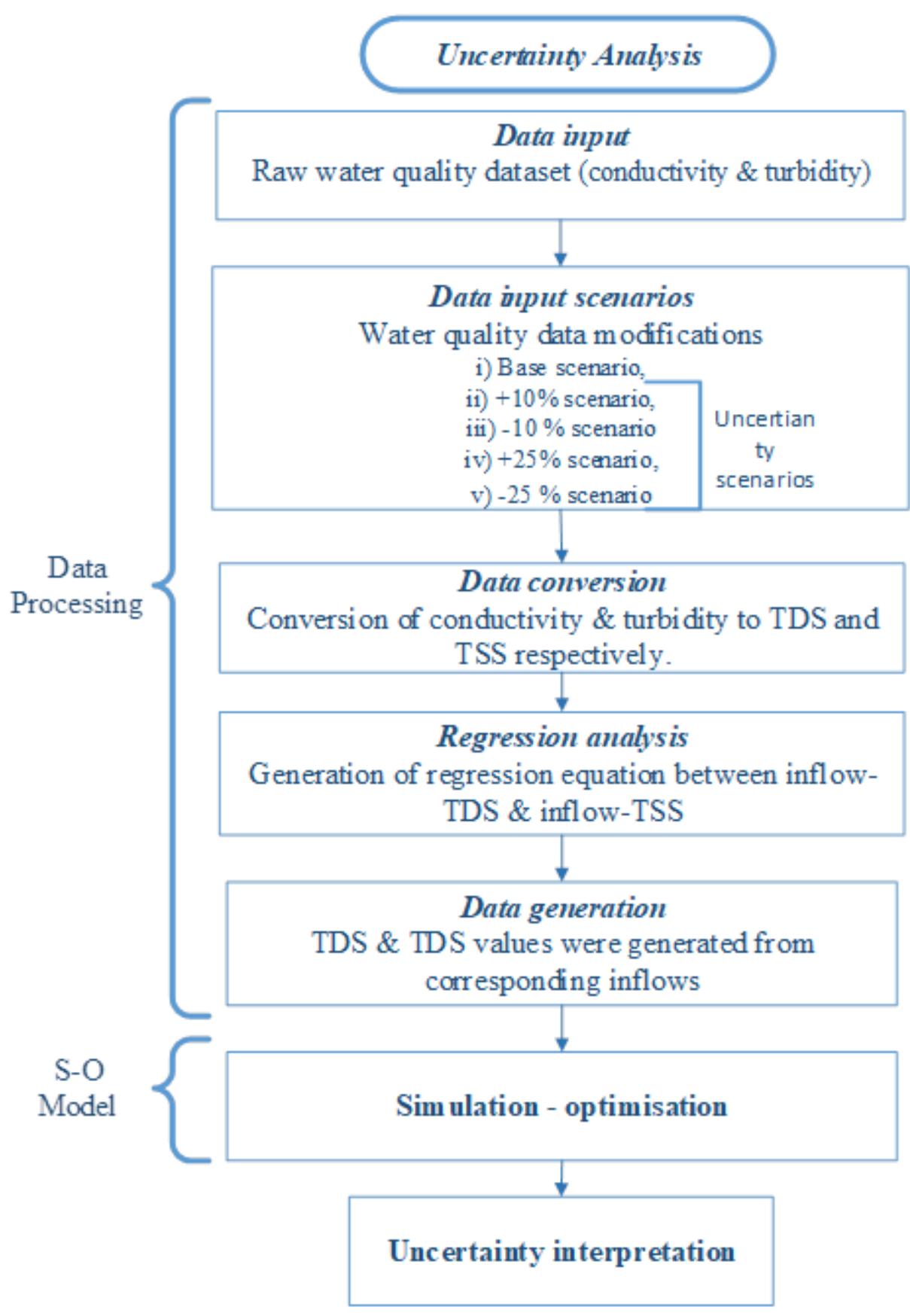

Figure 2

Stepwise uncertainty analysis 


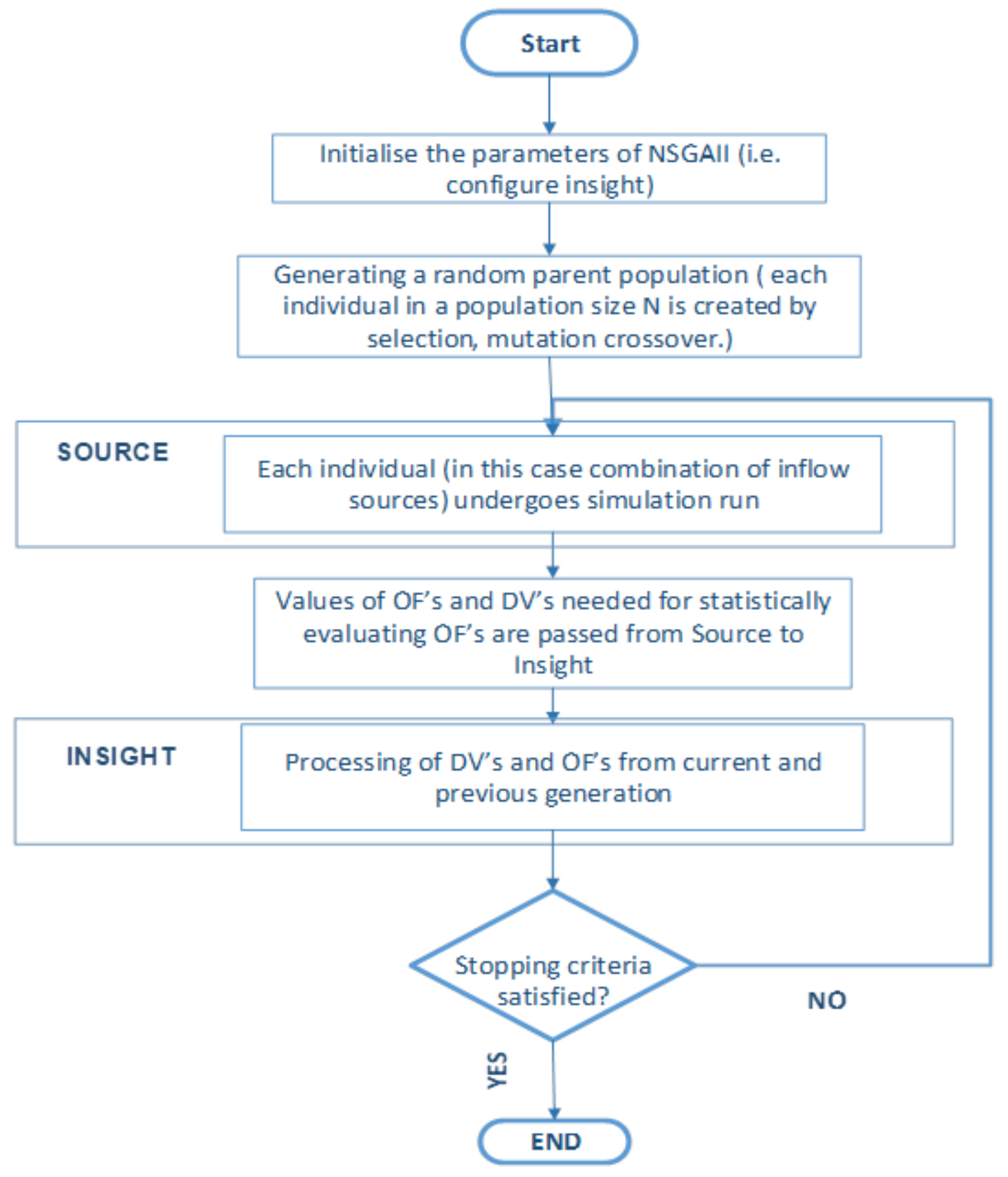

Figure 3

Flowchart showing of interaction between simulation and optimisation model 


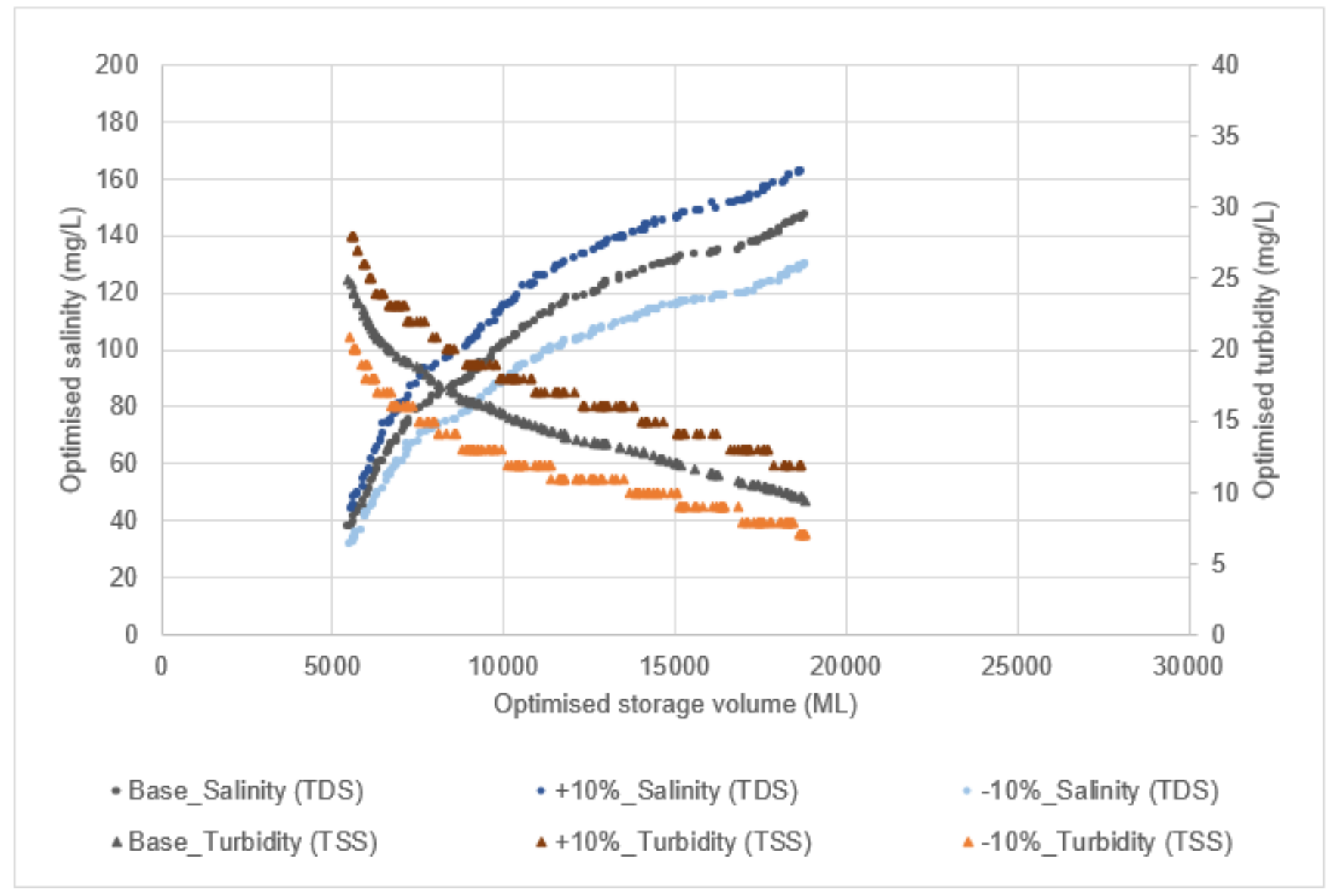

\section{Figure 4}

Optimal values of water quality and quantity for base scenario and $\pm 10 \%$ water quality uncertainty scenarios 


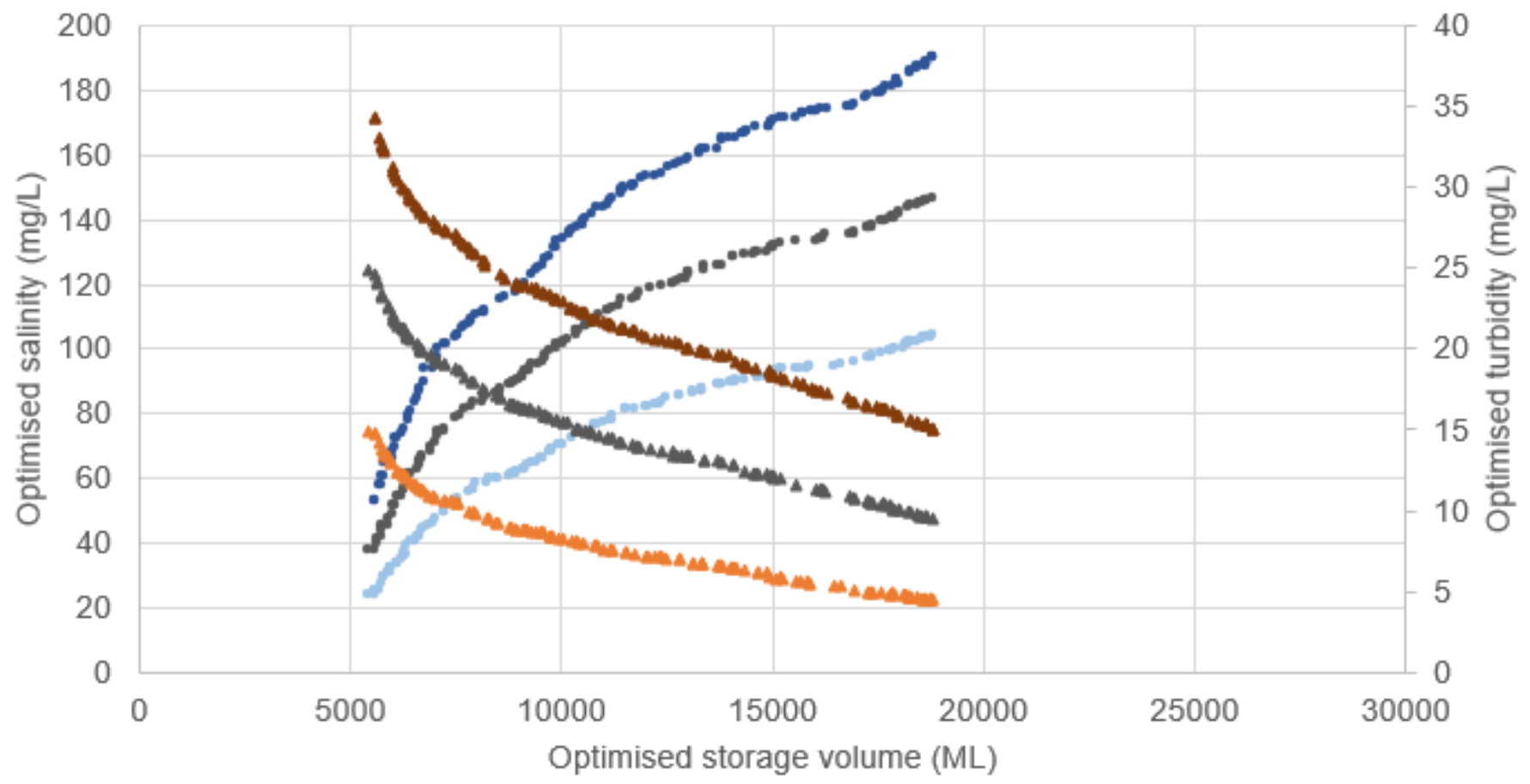

-Base_Salinity (TDS)

^ Base_Turbidity (TSS)
- +25\%_Salinity (TDS)

^ +25\%_Turbidity (TSS)
- $-25 \%$ Salinity (TDS)

^-25\%_Turbidity (TSS)

\section{Figure 5}

Optimal values of water quality and quantity for base scenario and $\pm 25 \%$ water quality uncertainty scenarios 


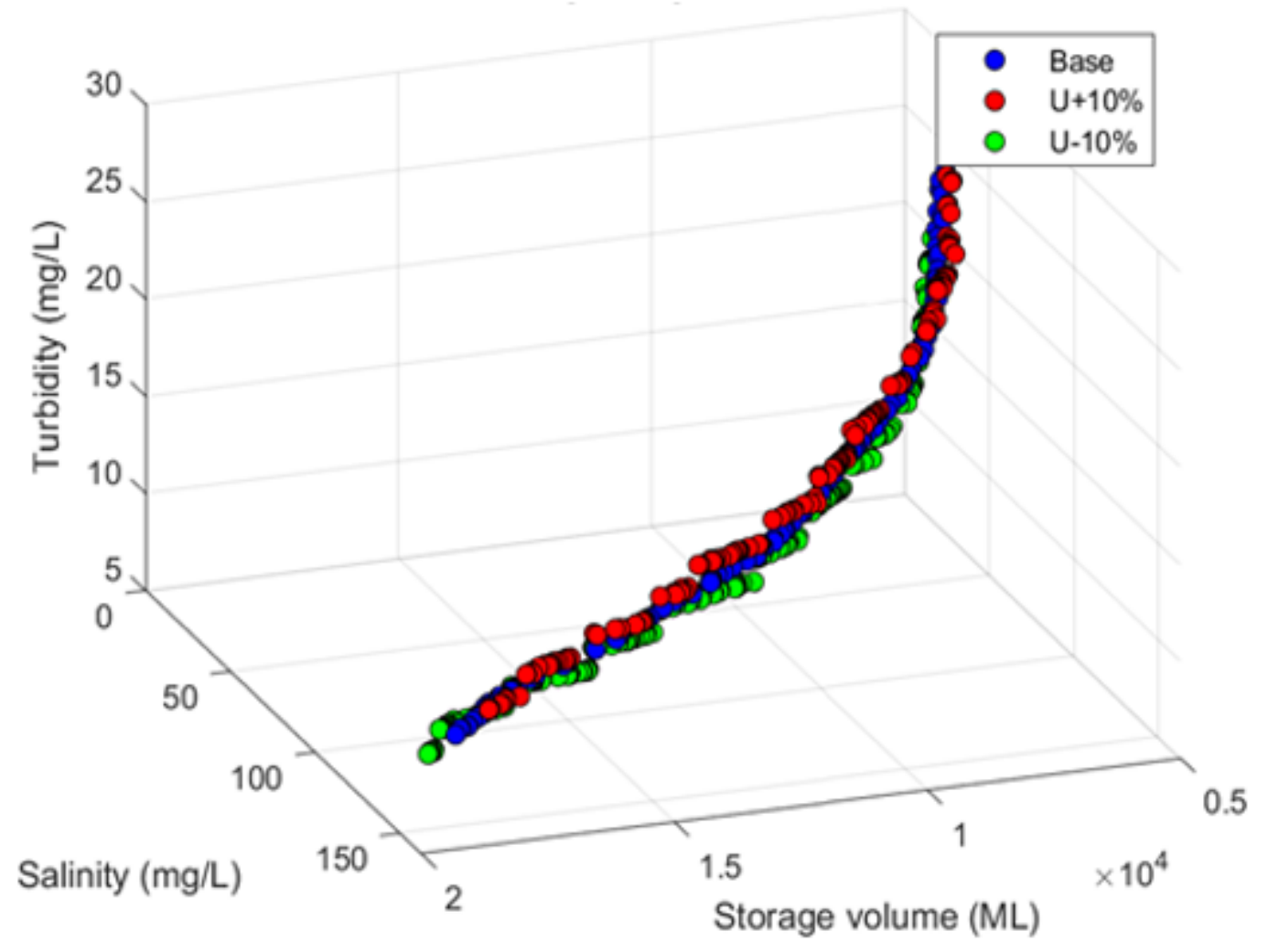

Figure 6

Comparing Pareto fronts of base scenario with $\pm 10 \%$ water quality uncertainty scenarios 


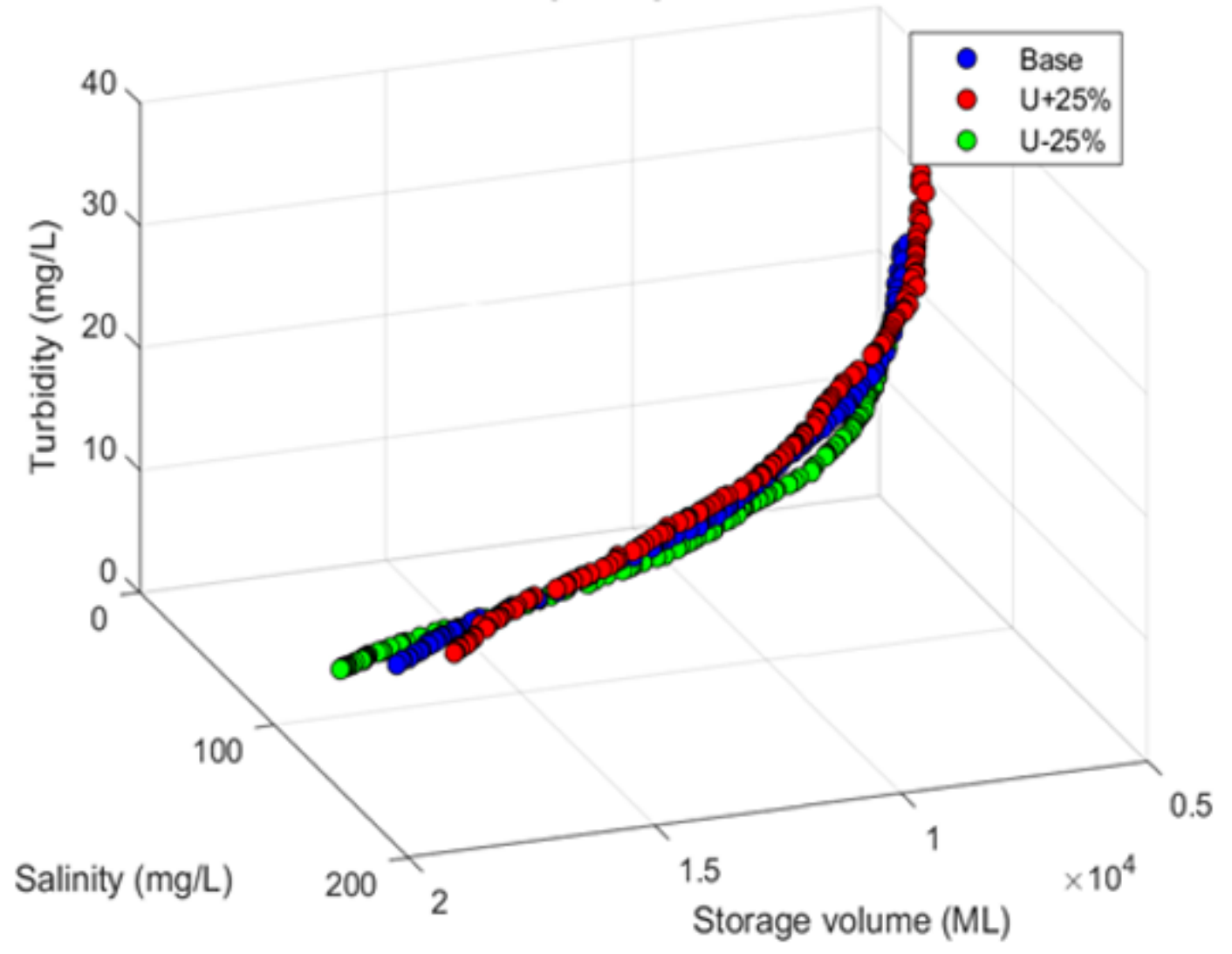

Figure 7

Comparing Pareto fronts of base scenario with $\pm 25 \%$ water quality uncertainty scenarios 